\title{
Towards a new health care system?
}

\author{
PATRICIA DAY, RUDOLF KLEIN
}

Over the past decade Britain has been moving, hesitatingly and haphazardly, towards a mixed economy of health care. The assumption that health care policy could be equated with what was happening to and in the National Health Service, an assumption that shaped national debate and decision making for more than three decades after the creation of the NHS, is beginning to look frayed at the edges. The expansion of the private sector has meant that no analysis of health care provision in Britain can ignore its role. Whether our concern is with equity or efficiency, issues of access or questions about the level of provision, the activities of the private sector have to be taken into account. In this paper we address some of the implications raised by this development, drawing on three newly published surveys of the field that between them provide a comprehensive picture of what has been happening. ${ }^{1 \cdot 3}$

Our starting point is that the NHS will continue to be responsible for most of the health care for most of the people for most of the time. For the trends analysed in the three reviews confirm the prediction of the Nuffield study, published three years ago, that the rate of expansion in private health care would not be sustained at the pace achieved at the turn of the decade. ${ }^{4}$ There has been a conspicuous drop, as the Economist Intelligence Unit analysis shows, in the annual rate of increase in the number of people subscribing to insurance schemes. In 1979 there was a rise of $16 \cdot 2 \%$, followed by one of $25.9 \%$ in the following year. By 1982 the annual rate of increase had fallen to $2.9 \%$, dropping to $1.9 \%$ in the following year. And although there is evidence of a pick up since then, there is no sign of a return to the boom years. Equally, although there continues to be a rise in the number of beds in independent hospitals, it is questionable how long this can be sustained. The numbers rose from 6758 in 1979 to 10174 in 1985 - and will have increased, it is estimated, by a further 850 by the end of 1986. Expansion, however, seems to have led to a drop in occupancy rates, indicating that there may be an oversupply of private beds at least in some parts of the country. The Economist Intelligence Unit survey quotes an estimate by the Association of Independent Hospitals that average bed occupancy rates in 1984 were no more than $65 \%$, compared with the notional break even point of $70 \%$ needed for financial viability.

In the case of nursing homes providing care for the elderly the picture is somewhat different. Here, too, there has been an expansion in the number of beds provided: the annual rate of increase was just over $8 \%$ between 1982 and $1984 .^{5}$ The dynamics of expansion, however, are somewhat different. Private acute care is overwhelmingly financed by private insurance. The Economist Intelligence Unit estimates that whereas in 1975 patients themselves paid $40 \%$ of the accounts in private hospitals, the rest being borne by insurance, by 1984 the proportion had fallen to $25 \%$ : a reminder, perhaps, that some of the expansion in the private insurance market may represent a shift in the way that private health care is financed. In contrast, nursing home care is largely personally financed, with an increasing share being taken not by the private insurance market but by state social security as a result of changes in the supplementary benefit rules in $1982 .{ }^{6}$ The figures of social security payments

\footnotetext{
Centre for the Analysis of Social Policy, School of Humanities and Social Sciences, University of Bath, Claverton Down, Bath BA2 7AY

PATRICIA DAY, BSC, research officer

RUDOLF KLEIN, MA, professor of social policy

Correspondence to: Ms Day.
}

do not distinguish between residents in nursing and residential homes. They therefore indicate the trend, rather than the size of the state's contribution to the private sector. But the trend is remarkable. In 1982 social security paid all or part of the fees of 15700 residents at a total cost of $£ 39$ million. By 1984 the equivalent figures were 42500 and $£ 190$ million respectively. ${ }^{7}$ The provision of care for the elderly therefore reflects a new pattern: the private provision of publicly financed care.

It is not clear whether or not this trend will continue. The Department of Health and Social Security seems to have stumbled

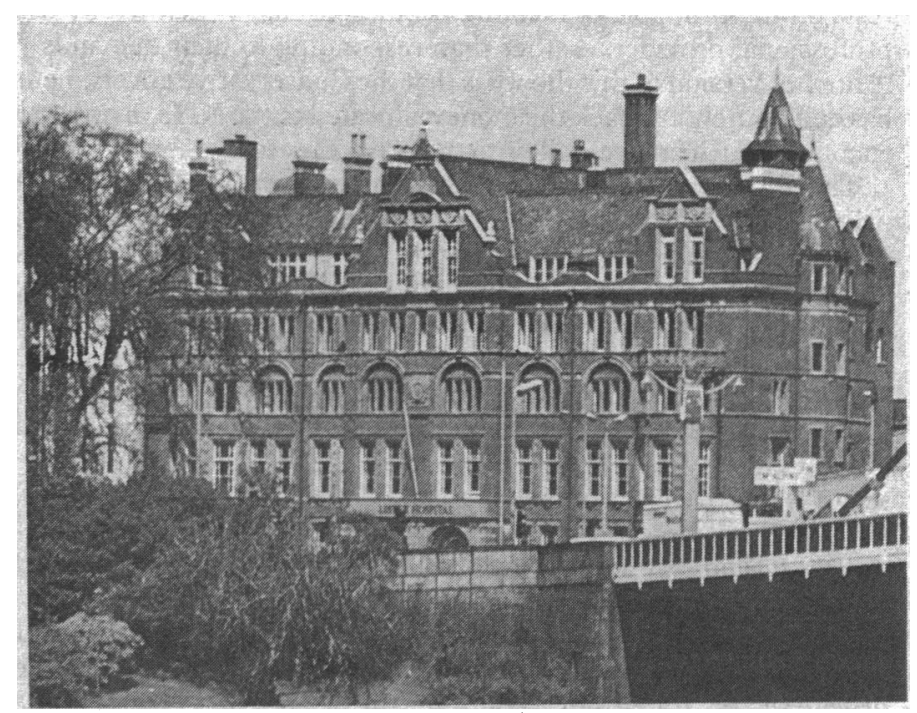

The Lister Hospital, a new private hospital in London.

into this policy by accident and is currently reviewing its commitments: the level of fees payable by social security has already been cut. Laing, however, is surely right to argue that the private sector of care for the elderly is likely to go on expanding, although the balance between nursing homes, residential homes, and sheltered housing may change. ${ }^{3}$ Demography alone-that is, the increase in the number of over $85 \mathrm{~s}$ - is likely to ensure an expanding demand. Equally important may be the changing economic position of the elderly. Poverty and retirement are no longer synonymous. ${ }^{8}$ The growth of occupational pension schemes and home ownership means that future generations of elderly are likely to be much better placed to exercise choice and to buy care than the present one.

Overall, then, the independent sector now accounts for about $7 \%$ of all spending on health care in the United Kingdom according to Laing's calculations. ${ }^{2}$ This compares with a probably overconservative estimate of $3 \%$ for 1976 cited by the Royal Commission on the National Health Service. ${ }^{9}$ All such figures must be treated with caution. For example, private spending by individuals on alternative medicine is difficult to quantify with precision. But it would seem safe to conclude that spending on private health care has increased considerably, now represents a substantial proportion of all expenditure, and may well creep up to a figure of $10 \%$ of the total over the next decade in the absence of any dramatic policy initiative. Assuming that there is no such dramatic policy initiative-a reasonable assumption, given the Conservative government's eagerness to declare its support for the NHS and the, perhaps not unrelated, overwhelming enthusiasm for it shown in all public 
opinion polls-what are the implications for the way in which we think about policy issues? In what follows we explore some, but by no means all, of the issues for the NHS raised by these developments.

\section{Why the expansion in private care?}

The best starting point for such an exploration is to try to understand why the expansion of the private sector should have taken off. This is not easy since, as we shall see, the evidence is contradictory and difficult to interpret. But there are at least two theories of explanation, with variations on each of them, which provide a basis for inquiry. The first might be called the "overspill theory." This rests on the contention that a tax financed national health service is bound to short change consumers-in the sense that collectively the nation will be prepared to provide fewer resources than individuals would be prepared to pay for their own health care ${ }^{10}$-and that an excess of demand will therefore spill over into the private sector. This is consistent with the fact that the NHS rests on the principle of meeting people's needs, as defined by the professional providers, rather than responding to their demands. A further version of this theory is that the Conservative government has deliberately cut back the money allocated to the NHS in order to encourage such an overspill into the private sector.

The alternative theory emphasises the positive attractions of the private sector. The argument is that the private sector offers a preferred pattern of health care. Indeed the medical profession has often asserted, in defence of the right to engage in private practice, that it gives an opportunity to provide medicine as it should be practised. Freed from the constraints imposed by working in the NHS, whose priorities are determined by the responsibility to provide a collective service, where the resources and time given to one patient may be at the cost of another, the clinician in the private sector is free to treat everyone as an individual. The two theories are, of course, not necessarily incompatible; they may well be complementary. And this is why, perhaps, it is so difficult to isolate and weigh up the contribution of either.

The overspill theory makes a great deal of sense in general, but does not adequately explain the timing of the expansion in the private sector. It helps to account for the balance of activities in the private sector: in particular, the Sheffield studies have analysed the strong bias towards elective procedures and minor surgery. ${ }^{1213}$ This is precisely what is to be expected given that the NHS's own bias is towards meeting needs rather than demands: the medical urgency of the presenting conditions may rate lower priority in the NHS's own scale of values than does the social urgency as perceived by the individuals concerned. A puzzle remains, however. Why should the overspill of demand suddenly have erupted in the second half of the 'seventies? It preceded the present government's financial squeeze on the NHS and has dropped (to judge by the insurance figures quoted earlier) just as the squeeze has become more intensive. It is difficult to correlate with changes in the length of waiting lists, an ambiguous indicator at the best of times. It is possible to invent any number of ad hoc explanations. For example, the rise in the late 'seventies may be put to the door of the Labour government, whose wages policy gave employers an incentive to offer health insurance protection as an extra reward and whose pay bed policy gave new visibility to the private sector while at the same time weakening the commitment of some consultants to the NHS. These are not altogether convincing and do not help with subsequent trends.

\section{Skewed distribution of care}

Moreover, these sort of explanations fail to address one of the main puzzles, documented by all the surveys under review. This is the skewed geographical distribution of private health care, whether acute or nursing home care. The use of private health care is, of course, strongly linked to social class: someone belonging to social class one is 11 times more likely to be covered by private insurance than a manual worker. ${ }^{14}$ But even when allowance is made for the differences in the social composition of the population in various parts of Britain, striking variations in coverage by private insurance remain. Thus coverage is $50 \%$ higher in Greater London than would be expected, and $50 \%$ lower in the north-while Scotland and Wales have an even lower proportion. And the same is true, as Laing shows, of the distribution of residential care for the elderlyalthough, unfortunately, his analysis does not distinguish between the different forms of provision. ${ }^{3}$ And these differences cannot be related to variations in the level of NHS resources-that is, there is no systematic evidence that demand for private care is highest in those parts of the country where the NHS is relatively underprovided. Thus the north (where demand for private care is low) is underprovided on the Resource Allocation Working Party formula while Greater London (where demand for private care is high) is overprovided. ${ }^{15}$ So the puzzle persists.

Taking the alternative theory, which is that the private sector offers a preferred pattern of health care for consumers, there is a similar problem. Again, this may well be largely true. But, once more, it fails to explain the timing of the take off in the expansion of spending on private care. Nor is it fully consistent with the evidence of the General Household Survey ${ }^{14}$ and other studies ${ }^{16}$ that even the insured use the private sector selectively, and tend to commute between it and the NHS. Thus the General Household Survey found that "among those with private insurance, more than half the inpatient stays and four fifths of the outpatient attendances were made under the NHS." In other words, use of the private sector does not imply rejection of the NHS, but seems to suggest a highly rational strategy for exploiting the special advantages of each. The private sector is seen by consumers to have certain, specific advantages, and is used selectively accordingly, rather than being embraced, whole hog, because of some special magic attaching to private medical practice as such. And it may be that the greater consumption and concentration of private health care in Greater London, and parts of southern England, reflects the fact that this is where the mobile, consumer oriented middle classes are concentrated, with somewhat different cultural values than their social equivalents in the north. This is a highly speculative hypothesis, of course. If it is at all correct and if southern attitudes today are anything like an accurate predictor of national values tomorrow then it is not unreasonable to assume that the selective shopper's approach to health care is likely to spread.

If this interpretation has any force then one possible implication to be drawn from the growth of the private sector is that the NHS might do well to ask why shoppers use consultant corner shops rather than the national supermarket. The NHS cannot suddenly provide elegant hotel accommodation in single rooms; neither can it respond fully to demands generated by new procedures. But consider some of the other advantages offered by the private sector. Firstly, there is its emphasis on preventive medicine, in the sense of early intervention to prevent deterioration in the patient's social and physical ability to function fully. Secondly, there is its ability to accommodate to the patient's timetable rather than that of the organisation providing the health care. The conventional wisdom here is that both the failure of the NHS to satisfy the demand for timely preventive medicine (notably elective surgery) and its inability to schedule operations and admissions to suit patients rather than staff are simply a function of inadequate resources.

There is a large dose of mythology in this conventional wisdom, if also an element of truth. In the case of orthopaedic services it has been shown that better management can both improve productivity and offer a more convenient service to patients. ${ }^{17}$ Indeed the two may go hand in hand, since better management means planning more efficiently, which includes planning the flow of patients rather than bringing them into hospital in an unexpected flurry. The real question may be why the NHS finds it so difficult to overcome organisational rigidities. And here, perhaps, the private sector provides some clues.

\section{Paradox in the acute sector}

For the private acute sector offers a paradox. The medical work done is carried out by the same consultants who perform in the 
NHS. Yet the way in which they work seems to be different in several respects. It is not just that lengths of stay in the private sector are shorter than in the NHS, although longer than in NHS pay beds; this might simply reflect the different social status and home environment of the patients, or other factors. ${ }^{18}$ It is that in private hospitals consultants suddenly discover that they can work perfectly satisfactorily without the retinue of registrars and junior doctors that is considered essential in the NHS. It is that in the private sector consultants can deliver what is generally presumed to be high quality medicine (there are no statistics) in hospitals that are frequently not much larger than a single ward in an NHS hospital. Even allowing for the difference between the more limited activities carried out in most private hospitals, as against the much greater range in acute NHS hospitals, this contrast calls into question the insistence of the consultant profession over the decades on having ever more complex and expensively equipped hospitals at their disposal. For in the private sector consultants seem to discover a flexibility, a readiness to make do with less technological back up, and an ability to use resources efficiently, which they do not show in the NHS. And it is this flexibility which, in part at least, helps to explain both the economic viability and the attractions to the consumer of the private sector.

So the growth of the private sector poses a challenge to the NHS to create for its staff the kind of environment that will enable them to show the creative flexibility and management flair that they show outside it. One factor may well be size: that flexibility is a function of organisational simplicity, and that organisational simplicity suffers as the size of an institution increases. If so the logic would be to move towards much smaller hospitals in the NHS, perhaps relying on the potentials of information technology to plug them into a network of back up expertise. ${ }^{19}$ Alternatively, the explanation may lie in the relative freedom of the private sector from the rules and restrictions imposed by professional organisations and trade unions in the NHS. If so the prospect for the NHS may be bleak, since it is difficult to see it successfully tackling professional and trade union restrictive practices (not to be equated, it must be emphasised, with wage or salary cutting: the aim surely should be higher earnings in return for greater flexibility).

If the NHS's new management structure cannot deliver more flexibility, if it cannot reproduce some of the conditions so successfully exploited by the private sector, then it may be that eventually a more radical solution will emerge. This is that the NHS may increasingly become the financier of health care provided by the private sector rather than being predominantly a producer. For once again there is a paradox. To the extent that the private sector depends on the market for its customers, so one of the principles shaping Britain's postwar consensus on health care policy will be eroded: the principle of equity - of allocating health care according to need, not people's ability to finance it. At present, the private health care market tends to accentuate inequality, even allowing for the fact that the middle classes who use it also tend to get a better deal out of the NHS than their less articulate, less pushy, and less informed fellow citizens. But the private production of health care does not, of itself, create inequities. If social and clinical criteria rather than the means of the patient determine access then private health care production is compatible with equity. This, of course, underlines the irony of the present government's inadvertent egalitarianism in health policy. By its accidental decision to support nursing home patients through the social security system it made available to the poor what previously had been available only to the well off.

\section{Uncomfortable implication for doctors}

The growth of the private sector has a further specific, direct, and perhaps uncomfortable implication for the medical profession. If public and private health care have to be regarded as part of one system, rather than as two discrete and separate phenomena, then does this not also logically apply to the income that doctors derive from the two sectors? The importance of this point may be illustrated by figures from the Economist Intelligence Unit survey. In 1977 the medical insurance schemes paid out $£ 27700000$ in medical fees of various kinds. In 1983 the equivalent figure was $£ 134900000$. In 1977 the medical fees represented an average of $£ 2000$ per consultant or $22 \%$ of the NHS salary drawn by a consultant at midpoint in the salary scale. ${ }^{20}$ By 1983 the fees represented an average of $£ 8300$ per consultant or $38 \%$ of the NHS salary. ${ }^{21}$ The figures need interpreting with caution. As presented they oversimplify. In 1977 many consultants were barred by their NHS contracts from engaging in private practice. In 1983 all NHS consultants were entitled to engage in some private practice. Moreover, well over half of the total fees, in both 1977 and 1983, went in payment to surgeons and anaesthetists. So the rewards of private practice are unequally distributed among consultants. Lastly, the figures do not take account of the fact, mentioned earlier, that there may have been a switch from individually financed to insurance financed private practice over the period. Even with all these reservations, however, it would seem clear that the medical profession has done well out of the growth of private practice. And it would be surprising indeed if the review body were not to take account of the fact in future when comparing medical earnings with those in other professions.

The importance of the growth of the private sector may, therefore, eventually turn out to be measured in terms of its effects on the way in which we think about policy issues in the arena of health care. From this perspective it is less its absolute size that matters as the style in which it operates. It is this that represents a challenge to many of the conventional assumptions about the NHS. We may, and probably should, continue to use the ideals and values implicit in the creation of the NHS to judge the impact of developments both in the service itself and in the private sector. In particular, we should go on worrying about social equity in the distribution of and access to health care. But this should not stop us from asking questions about what the NHS can learn, in terms of its organisation, manpower, and relationship with consumers, from the rest of the health care system.

\section{References}

1 Grant C. Private health care in the UK: a review. Special report No 207. London: Economist Intelligence Unit, 1985.

2 Laing W. Private health care 1985. London: Office of Health Economics, 1985.

3 Laing W. Care of elderly people: the market for residential and nursing homes in Britain. London: Laing and Buisson, 1985 .

4 McLachlan G, Maynard A, eds. The public/private mix for health. London: The Nuffield Provincial Hospitals Trust, 1982

5 Day $\mathrm{P}$, Klein R. Maintaining standards in the independent sector of health care. $\mathrm{Br} \mathrm{Med} \mathcal{F}$ 1985;290:1020-2.

6 Challis L, Day P, Klein R. Residential care on demand. New Sociery 1984;April 5:32.

7 Social Security Advisory Committee. Proposals for the supplementary benefit (requirements and resources) miscellaneous provisions regulation 1985. London: HMSO, 1985. (Cmnd 9466.)

8 Department of Health and Social Security. Reform of social security. Vol 2. London: HMSO, 1985. (Cmnd 9518.)

9 Royal Commission on the National Health Service. Report. London: HMSO, 1979. (Cmnd 7615.)

10 Harris R, Seldon A. Over-ruled on welfare. London: Institute of Economic Affairs, 1979.

11 Klein R. The politics of the National Health Service. London: Longmans, 1983.

12 Williams BT, Nicholl JP, Thomas KJ, Knowelden J. Contribution of the private sector to elective surgery in England and Wales. Lancet 1985;ii:89-92.

13 Williams BT, Nicholl JP, Thomas KJ, Knowelden J. Analysis of the work of independent acute hospitals in England and Wales, 1981. BrMed $\mathcal{F}$ 1984;289:446-8.

14 Office of Population Censuses and Surveys. General household survey 1982. London: HMSO, 1984.

15 Social Services Committee. Fourth report from the Social Services Committee 1983-84: public expenditure on the social services. London: HMSO, 1984. (HC 395.)

16 Horne D. A survey of patients in the private sector. Hospital and Health Services Review 1984;80:70-2.

17 Department of Health and Social Security. Orthopaedic services. Waiting time for outpatient appointments and inpatient treatment. London: HMSO, 1981. (Duthie report.)

18 Williams BT, Nicholl JP, Thomas KJ, Knowelden J. Differences in length of stay for surgery in the NHS and the private sector in England and Wales. Br Med $\widetilde{J} 1985 ; 289: 446-8$.

19 Scrivens E. Policy, power and information technology in the National Health Service. Bath Social Policy Paper. Bath: University of Bath, 1985.

20 Review Body on Doctors' and Dentists' Remuneration. Ninth report 1979. London: HMSO, 1979. (Cmnd 7574.)

21 Review Body on Doctors' and Dentists' Remuneration. Fourteenth report 1984. London: HMSO, 1984. (Cmnd 9256.) 